\title{
Ampliando Comportamentos Pró-Éticos dos Alunos: Relato de Pesquisa e Intervenção com Educadores do Ensino Fundamental
}

\author{
Alessandra Turini Bolsoni-Silva \\ Ana Cláudia Moreira Almeida Verdu \\ Kester Carrara \\ Ligia Ebner Melchiori \\ Lúcia Pereira Leite ${ }^{1}$ \\ Sandra Leal Calais \\ Programa de Pós-Graduação em Psicologia do Desenvolvimento e Aprendizagem \\ da Universidade Estadual Paulista Júlio de Mesquita Filho, Bauru, Brasil
}

\begin{abstract}
Resumo
O objetivo desta pesquisa foi o de descrever efeitos de uma intervenção realizada com educadoras de primeira série do ensino fundamental, buscando ampliar habilidades sociais básicas compatíveis com repertórios pró-éticos. Participaram cinco educadoras e 57 alunos e foram aplicados dois instrumentos, a Escala de Comportamento Infantil B. de Rutter para professores (ECI-B) e o Questionário de Respostas Socialmente Habilidosas para Professores (QRSH-Pr); e realizadas filmagens de situações de sala de aula pré e pós intervenção. As educadoras participaram de uma proposta de formação continuada, momentos em que se refletiram questões teóricas vinculadas à formação e desenvolvimento ético-moral, além de temáticas diversas, que emergiram dos resultados da aplicação preliminar dos instrumentos utilizados. Os resultados gerais mostraram aumento na interação positiva aluno-educador, na exibição de comportamentos socialmente hábeis, além de diminuição dos indicativos de problemas de comportamento, ampliando assim os comportamentos pró-éticos na realidade investigada. Diante de tais dados, que indicam o envolvimento de docentes e a sensibilidade dos alunos às contingências programadas, parece auspicioso o emprego de procedimentos sistemáticos de ensino mediante rearranjo de contingências para formação continuada dirigida a temas transversais relevantes, como o da ética nas relações interpessoais, a partir do contexto escolar.
\end{abstract}

Palavras-chave: Comportamento pró-ético, comportamento pró-social, ensino fundamental, intervenção, formação continuada.

\section{Extending Pro-Ethical Behavior of Students: Research and Intervention with Primary School Teachers}

\author{
Abstract \\ The aim of this research was to describe effects of an intervention with educators from the first grade of \\ elementary school, seeking to expand basic social abilities consistent with pro-ethical repertoires. Par- \\ Endereço para correspondência: Departamento de Psicologia, Faculdade de Ciências de Bauru, Universidade \\ Estadual Paulista Júlio de Mesquita Filho, Av. Eng. Luiz Edmundo Carrijo Coube, 14-01, Vargem Limpa, \\ Bauru, SP, Brasil 17033-360. E-mail: bolsoni@fc.unesp.br, anaverdu@fc.unesp.br, kester.carrara@uol.com. \\ br,1melch@fc.unesp.br, lucialeite@fc.unesp.bre scalais@fc.unesp.br \\ Este estudo derivou de um projeto maior "Ensino fundamental, aprendizagem e desenvolvimento: um aporte \\ da Psicologia à construção da cidadania na escola", processo 2004/14157-0, Edital de Ensino Público da \\ Fundação de Amparo à Pesquisa do Estado de São Paulo (FAPESP).
}


ticipated five teachers and 57 students participated and they were applied to the Rutter Child Behavior Scale B. for Teachers (ECI-B) and Questionnaire of Socially Adept Answers for Teachers (QRSH-Pr), beyond classroom situations films before and after intervention. The educators had also participated of a proposal of continued formation, moments in that they had reflected theoretical issues related to training and developing ethical and moral as well as diverse topics, which emerged from the preliminary application of the instruments utilized. The overall results showed an increase in positive student-teacher interaction, in the view of socially skillful behaviors, beyond reduction of indicators of behavior problems, thus extending the pro-ethical behaviors in the investigated reality. These data indicate the involvement of teachers and sensitivity of students with programmed contingencies. In this case, the use of systematic procedures and teaching rearrangement contingencies for continuous formation seems prosperous, especially if targeted themes transverse relevant, as the ethics of interpersonal relationships in the school context.

Keywords: Pro-ethical behavior, pro-social behavior, intervention, fundamental education, continuous formation.

\section{Ampliación de la Conducta Proética de los Estudiantes: Investigación e Intervención con los Educadores de Escuela Primaria}

\section{Resumen}

El objetivo de este estudio fue describir los efectos de una intervención con los educadores de las primeras series de la escuela primaria, buscando ampliar capacidades sociales básicas compatibles con repertorios favorables a la ética. Cinco educadores y 57 estudiantes participaron y se aplicó la Escala de Conducta Infantil B. de Rutter para profesores (ECI-B) y el Cuestionario respuestas socialmente cualificadas para Maestros (QRSH-Pr), además de películas de situaciones en el aula antes y después de la intervención. Los educadores también participaron de una propuesta de formación continuada, momentos donde si habían reflejado preguntas teóricas relacionadas con la formación y el desarrollo de diversos temas éticos y morales, así como los que habían emergido de los resultados preliminares de los instrumentos usados. Los resultados generales mostraron un aumento en la interacción positiva de los estudiantes y maestros, en la exposición de comportamientos socialmente calificados, y la reducción de los indicadores de problemas de conducta, así ampliando los comportamientos que llevan a la ética en la realidad investigada. Teniendo en cuenta estos datos, los cuales indican la participación de los docentes y la sensibilidad de los alumnos ante las contingencias programadas, parece prometedor el uso de procedimientos sistemáticos de enseñanza mediante la reorganización de las contingencias para la formación continua dirigida a los temas transversales relevantes, tales como la ética en las relaciones interpersonales, partiendo del contexto escolar.

Palabras clave: Comportamiento favorable a la ética, conducta pro-social, intervención, educación primaria, formación continua.

Políticas públicas comprometidas prioritariamente com a ampliação, fortalecimento e adequação dos conteúdos curriculares têm predominado nas últimas décadas, em contrapartida a iniciativas esparsas para qualificação da clientela educacional com vistas ao adequado emprego de tais conhecimentos no contexto das interações sociais. Mais recentemente, no âmbito dos mo- vimentos e do processo de consolidação democrática do país, a ênfase nos conteúdos passou a ceder espaço para a ênfase numa formação ético-moral que procure levar à preparação de cidadãos que participem das decisões políticas, no emprego do conhecimento dentro de um contexto cooperativo e na recuperação de valores sólidos de caráter, que permitam a consolidação das 
instituições sociais. Essa tendência, apoiada de modo incipiente nos planos políticos e em vários programas de ação dos governos federal, estaduais e municipais dos últimos anos, tende agora a ampliar-se e estabelecer-se como meta inalienável da completa formação acadêmica em todos os níveis de ensino. O quê ensinar (preocupação com o conteúdo) e o para quê ensinar (preocupação com as finalidades) seguem agora adiante das já tradicionais ideias do ensino significativo: buscam, naturalmente, a relevância social e a compatibilidade entre os conteúdos aprendidos e as demandas sociais, mas, além disso, remetem a uma exigência cada vez mais clara dos tempos atuais, que se centra na formação ética geral do cidadão. Em outras palavras, está cada vez mais clara, em documentos orientadores, como a Lei de Diretrizes e Bases (LDB; Lei n ${ }^{\circ}$ 9.394, de 20 de dezembro de 1996), os Parâmetros Curriculares Nacionais (PCNs; Ministério da Educação e do Desporto, 1999) e o Referencial Curricular para Educação Infantil (RCNEI; Ministério da Educação e do Desporto, 1998), a preocupação geral com os temas transversais, em particular a formação ético-moral destinada à capacitação da população para contribuir com a consolidação dos melhores valores sociais compatíveis com a cidadania. No entanto, há consenso, nesses documentos, de que a escola pode cumprir uma parte importante do papel destinado ao processo educativo para a instalação e consolidação de repertórios comportamentais que assegurem a formação de cidadãos plenamente conscientes de seus deveres e direitos. Além dos documentos oficiais já citados (aos quais pode ser aduzido o texto sobre ética na escola produzido pelo Ministério da Educação [MEC], de 2004), o tema da preparação do educando enquanto cidadão que passa a se ocupar de valores morais importantes que integram o indivíduo às questões de interesse coletivo têm sido objeto, na literatura - não sem enfrentar aspectos polêmicos - de pesquisas e reflexões relevantes (e.g., Menin, 2002; Nucci, 2000; Oliveira, 2001).

Mediante esse cuidado com o reconhecimento da responsabilidade apenas parcial embora central - da escola, torna-se relevante o desenvolvimento de pesquisas que busquem o aprimoramento de estratégias e instrumentos didáticos de ensino responsáveis por capacitar educadores a lidarem com as dimensões éticas dos repertórios comportamentais dos seus alunos. Para além do também necessário cuidado com a excelência do conteúdo, a escola contemporânea de qualidade deve ocupar-se em contribuir para uma sólida preparação do seu corpo discente, no sentido de que este se capacite para interagir, socialmente, em conformidade com os melhores princípios de urbanidade nas relações interpessoais, assim como em consonância com o pressuposto da colaboração e compartilhamento com o coletivo, na perspectiva altruísta do preparar-se para respeitar deveres e direitos e contribuir para a consolidação de uma sociedade apoiada nas bases da justiça social. Note-se, no entanto, que (além da família, naturalmente), a escola constitui uma das primeiras e mais fundamentais instâncias onde se deveria aprender e apreender os conceitos essenciais de uma convivência respeitosa, cooperativa e construtiva, por certo valores éticos consagrados como dos mais básicos para uma formação cidadã. Uma vez que considerados como uma espécie de pré-requisitos para uma vida social integrada e integradora entre os participantes de qualquer núcleo comunitário, esses valores iniciais podem ser apreendidos no contexto da escola enquanto os primeiros sinais de uma boa formação social. Enquanto tal (como primeiras experiências e como pré-requisitos e condição preparatória e favorecedora de uma vida social digna), esses repertórios transversais podem ser ensinados pela escola e constituem, verdadeiramente, repertórios pró-sociais, no sentido de que nuclearão aprendizagens mais complexas e prepararão a criança na direção de uma formação cidadã. A expressão “comportamentos pró-sociais", nesse sentido, é uma referência às ações básicas indispensáveis à criança em formação para sua vida social de modo geral, estando aí incluídas as formas de aproximação aos demais, a ideia de convivência com o grupo, a noção clara dos procedimentos socialmente polidos das interações humanas. Por outro lado, quando se mencionam os "comportamentos pró-éticos", estes também se referem a pré-requisitos, porém, embora também cons- 
tituam repertórios sociais e - especialmente no contexto da infância - "pró-sociais", são, especificamente, comportamentos que revelam o início da integração social mediante a incorporação de valores éticos que preparam para o exercício integral da cidadania. Tais comportamentos são encontrados na literatura sob a frequente rubrica de comportamentos "pró-éticos". Repertórios pró-éticos são constituídos de interações sociais básicas que precedem uma vida adulta cidadã, mas apresentam uma peculiaridade, qual seja a de serem os rudimentos para as escolhas éticas que nortearão ações do indivíduo quando adulto. Para exemplificar, ao educar para a boa cooperação e o compartilhamento de recursos instrumentais ou didáticos (livros, canetas, lápis), também se está ensinando à criança os pressupostos mais básicos para uma vida adulta (cidadã) que exige obedecer algumas regras de convivência urbana, polida, respeitosa à propriedade alheia. Se, por um lado, uma dimensão ética implica interação social, por outro, comportamentos pró-éticos podem ser entendidos como constituindo uma subcategoria dos comportamentos sociais, uma vez que exigem a escolha de valores básicos que futuramente solidificarão uma atuação social do indivíduo baseada em respeito a direitos e deveres numa sociedade igualitária e justa (Betetto \& Carrara, 2009; Carrara, 1996, 1999, 2000; M. F. Ferreira \& Carrara, 2009; Rocha \& Carrara, 2011).

Del Prette e Del Prette (2003) relatam a importância de se destacar o desenvolvimento de valores positivos e de comportamentos pró-sociais na escola, com ênfase à empatia, solução de problemas interpessoais e controle da impulsividade e da raiva. A literatura sugere, em geral, que o ensino de Habilidades Sociais - por exemplo, as pró-éticas e pró-sociais - poderia ser realizado de modo compatível com o conteúdo acadêmico ensinado, ao mesmo tempo em que deveria enfatizar uma perspectiva cooperativa entre os componentes da comunidade acadêmica.

As Habilidades Sociais (HS) têm sido investigadas por Del Prette e Del Prette (2002) como um campo teórico-prático que visa descrever repertórios sociais, bem como tecer explicações acerca do surgimento e da manutenção dos mesmos. Para Caballo (1995) não há uma definição de consenso sobre habilidades sociais, ainda que o termo tenha sido usado para designar um conjunto de habilidades aprendidas. Assim, comportamento socialmente habilidoso ou mais adequado refere-se à expressão, pelo indivíduo, de atitudes, sentimentos, opiniões, desejos, respeitando a si próprio e aos outros, implicando, em geral, a resolução dos problemas imediatos, bem como na diminuição da probabilidade de problemas futuros (Caballo, 1991).

Caldarella e Merrell (1997), ao descreverem habilidades sociais específicas para crianças e adolescentes, apontam as seguintes categorias: (a) habilidades de relacionamento com colegas como elogiar, oferecer ajuda ou assistência, convidar para brincar; (b) habilidades de automanejo como concordar com outros quando apropriado, aceitar críticas, cooperar com outros; (c) habilidades acadêmicas como executar tarefas independente e individualmente, ouvir e cumprir as instruções do professor, utilizar o tempo adequadamente; e (d) habilidades de obediência como seguir instruções e regras, completar tarefas e guardar apropriadamente brinquedos e objetos. Esses comportamentos podem ser ensinados na interação do adulto com a criança. Nesse sentido, a análise dessas interações constitui aspecto relevante nessa proposta, uma vez que o comportamento humano é dotado de sensibilidade ao ambiente, mas, sobretudo a um aspecto especial desse ambiente, isto é, a sensibilidade ao que fazem outros membros da espécie.

Adicionalmente, pesquisadores afirmam que comportamentos socialmente habilidosos previnem o surgimento de problemas de comportamento (Del Prette \& Del Prette, 2002). Tal relação pode ocorrer à medida que as crianças, ao interagirem mais positivamente com as pessoas de sua convivência, aumentam a probabilidade de obter reforçamento social. Nessa linha de raciocínio, tais comportamentos poderiam propiciar "saltos" comportamentais (Rosales-Ruiz \& Baer, 1997), que são mudanças comportamentais importantes por permitirem que a criança encontre contingências relevantes para a aprendizagem social ou acadêmica. Por outro lado, Bolsoni-Silva e Del Prette (2003) definem 
problema de comportamento, considerando tanto a topografia quanto a funcionalidade da resposta, enquanto qualquer comportamento que pode prejudicar "saltos" comportamentais, sendo o caso de externalizantes, como roubar, mentir e agredir (Achenbach \& Edelbrock, 1979) ou então internalizantes, como ansiedade e tristeza (Achenbach \& Edelbrock, 1979), os quais podem produzir tanto punições no contexto escolar quanto comportamentos de isolamento social. Bolsoni-Silva (2008) define ainda problema de comportamento como qualquer comportamento que pode prejudicar a emissão de comportamentos que dão acesso a ambientes capazes de estimular positivamente a criança e, portanto, com potencial de aprendizagem de habilidades importantes.

Embora seja conhecida, evidentemente, a complexidade do processo de discussão e análise da questão do conceito de cidadania, que ocupa dimensões filosóficas, educacionais e sociológicas, toma-se como finalidade básica, na presente pesquisa, identificar, descrever e analisar efeitos de uma proposta de formação continuada de educadoras de segundo ano do Ensino Fundamental, para lidarem com os repertórios comportamentais de seus alunos, buscando ampliar habilidades sociais básicas compatíveis com os repertórios pró-éticos, mediante o aprimoramento de estratégias didático-metodológicas específicas.

\section{Método}

\section{Participantes}

Participaram da pesquisa cinco educadoras (designadas como A, B, C, D e E) de cinco classes de segundo ano do Ensino Fundamental de uma EMEF (Escola Municipal de Educação Fundamental), da rede pública de ensino, de uma cidade do centro-oeste paulista. Também participaram 57 alunos, selecionados das cinco classes, por indicação das suas respectivas professoras, totalizando 29 do sexo feminino e 28 do masculino, com idade de sete anos. As professoras foram orientadas a indicar uma criança que julgavam ser habilidosas nas interações sociais e uma que acreditavam ter dificuldades nas interações.

\section{Material e Instrumentos}

Foi utilizada uma filmadora digital para registro das interações entre educador e aluno e os seguintes instrumentos:

Escala de Comportamento Infantil B. de Rutter para professores (ECI-B; tradução Santos, 2002), que avalia a frequência de comportamentos considerados indicativos de problemas. A escala é composta por 26 itens com descrições de comportamentos de alunos como, por exemplo, "briga com outras crianças". Cada item tem três alternativas de resposta: o comportamento descrito se aplica (escore 2), aplica-se em parte (escore 1) ou não se aplica (escore 0 ) à criança. A escala tem ponto de corte escore superior a 9 - acima do qual se considera que a criança apresenta problemas de comportamento (clínico) - com alfa de Cronbach de 0,782 , podendo ser considerado satisfatório.

Questionário de Respostas Socialmente Habilidosas para Professores (QRSH-Pr; Bolsoni-Silva, Marturano, \& Loureiro, 2009), validado com boa consistência interna (alfa de Cronbach $=0,94)$. O QRSH-Pr é composto por uma lista com 27 itens de comportamentos socialmente habilidosos apresentados por crianças, no qual os educadores devem responder se um comportamento se aplica (escore 2), se aplica em parte (escore 1) ou não se aplica (escore 0). Os escores são somados, permitindo o escore total da criança avaliada. A análise fatorial conduzida com o instrumento permitiu obter os seguintes fatores, a partir do agrupamento dos itens: (a) Sociabilidade e Expressividade Emocional - tem relações positivas, mostra interesse pelos outros, faz amigos, expressa frustração, comunica-se, expressa desejos, expressa direitos, expressa carinhos, brinca com colegas, usualmente fica de bom humor, faz elogios, cumprimenta, interage de forma não verbal, participa de grupos; (b) Iniciativa Social - toma a palavra, expressa opiniões, participa de temas de discussão, toma iniciativas, negocia e convence, presta ajuda; (c) Busca de Suporte - procura atenção, faz pedidos, faz perguntas; (d) Não se intimidar. O instrumento também apresenta validade discriminativa e preditiva quanto aos indicativos de problemas de comportamentos. 


\section{Procedimento de Coleta de Dados}

$\mathrm{O}$ delineamento da pesquisa consistiu de três etapas (I, II e III). De maneira geral a primeira etapa caracterizou o comportamento das crianças via relato dos educadores por meio dos instrumentos adotados; a segunda etapa consistiu na intervenção junto às educadoras; a terceira etapa sondou o comportamento das crianças após a intervenção, pelos mesmos instrumentos da etapa inicial. Uma melhor descrição das etapas é apresentada a seguir.

\section{Etapa I.}

Informação dos objetivos e procedimento das etapas da pesquisa aos educadores e aos responsáveis legais pelos alunos que, estando de acordo, assinaram um Termo de Consentimento Livre e Esclarecido, conforme resolução 196/96, do Conselho Nacional de Saúde (1998; Ministério da Educação e do Desporto, 1998).

Os comportamentos das crianças foram avaliados pelas educadoras, que responderam aos dois instrumentos, ECI-B e QRSH-PR, nos quais os entrevistadores fizeram as perguntas oralmente e registraram respostas, depois transcritas para uma planilha de dados.

Realização de filmagens de interações entre educadores e crianças, em sala de aula. Foram realizadas duas filmagens em cada classe, com duração de 20 minutos cada. Foram adotados os procedimentos com relação à técnica de filmagem: (a) ser realizada por profissional capacitado para a atividade; (b) equipamento posicionado em local de onde seja possível focalizar a situação de ensino e aprendizagem; (c) horários de filmagens programados pelos pesquisadores, impossibilitando o preparo antecipado e intencional da educadora (Leite \& Aranha, 2005). Buscou-se o registro da prática pedagógica das professoras em situação interativa com seus alunos, assim as filmagens foram realizadas durante a apresentação da atividade à classe, fato que ocorria no início do período da aula ou logo após o recreio. O recurso de filmagens tem-se mostrado eficaz nas pesquisas que objetivam investigar interações sociais, pois possibilita analisar o fenômeno investigado a partir da obser- vação direta, do registro e posterior análise dos dados (Dessen, 1996; Leite, 2003).

\section{Etapa II.}

Foram discutidos 12 temas com as educadoras, em seis sessões de intervenção, sob coordenação da equipe de pesquisadores, nas dependências da universidade, em período noturno. Os encontros abordaram temas definidos a partir da literatura e dos dados obtidos com a aplicação dos instrumentos. Sendo eles: Sessão 1 - Avaliação de expectativas, discussão de regras para o grupo e definição de comportamentos pró-sociais e pró-éticos, bem como dificuldades encontradas para a sua promoção; A diversidade humana na Educação; Planejamento de condições educativas que atendam a questão da diversidade; Comunicação (respeitar a identidade da criança, fazer perguntas, iniciar conversação, olhar). Sessão 2 - Expressão de sentimentos positivos, elogios, dar e receber feedback positivo; Direitos Humanos, incluindo respeito à diversidade. Sessão 3 - Expressão de opiniões (concordância ou discordância), ouvir opiniões (concordância ou discordância); Expressão de sentimentos negativos, dar e receber feedback negativo; Fazer e recusar pedidos, explicitando com clareza as razões para tal. Sessão 4 - Como lidar com críticas (fazer e receber), admitir os próprios erros, pedir desculpas; Estabelecimento de limites. Sessão 5 - Consistência na forma de interagir com a criança; Desenvolvimento infantil: comportamentos "desejados" e "indesejados". Questionar regras sobre o que é certo e errado fazer; Ignorando comportamentos "indesejados"; valorizar comportamentos "desejados", dar atenção, expressar afeto; Promoção de mudança de comportamento, dar regras, valorizar seguimento de regras, negociar. Sessão 6 - Análise do progresso da aprendizagem; Relacionamento com a comunidade escolar (pais e servidores) e orientação no convívio com a diversidade.

Uma seleção das filmagens das interações sociais ocorridas em situação de ensino-aprendizagem foi utilizada como subsídio para a análise e reflexão sobre a prática educacional. $\mathrm{O}$ critério utilizado foi analisar momentos em que a edu- 
cadora estivesse em processo de interação com seus alunos por maior período de tempo. As seis sessões tiveram a estrutura descrita a seguir.

A primeira parte de cada sessão investigou os acontecimentos da semana relacionados à prática cotidiana de sala de aula. Na sequência, foram apresentadas e modeladas habilidades (das mais simples para as mais complexas) para que as educadoras pudessem estimular o desenvolvimento dos escolares, com prioridade para instalação e consolidação de comportamentos pró-éticos e pró-sociais.

O grupo discutiu cada uma dessas habilidades considerando o que cada educador já sabia e executava, bem como as dificuldades que cada um encontrava no processo de ensinar. Estratégias de ação dos educadores foram sistematicamente abordadas, mediante a utilização de procedimentos típicos para a promoção dos comportamentos apropriados e redução de comportamentos incompatíveis com os pró-éticos. As habilidades apontadas são básicas, todavia puderam ser alteradas e ampliadas conforme as prioridades apontadas pelo grupo de educadoras.

O processo de formação continuada constou de exposição teórica dialogada acerca de diferentes temáticas, quando eram identificadas dificuldades encontradas pelos educadores e sugeridas as possibilidades de resolução de problemas, a partir de exemplos do cotidiano, com o uso de estratégias e recursos diferenciados de apoio didático-pedagógico. Destaca-se que por formação continuada entende-se, em âmbito educacional, toda atividade em que o educador participa ativamente, buscando conhecer melhor o seu cotidiano, através da reflexão embasada no tripé prática-teoria-prática, ou seja, ao analisar sua prática pedagógica à luz de preceitos teóricos na busca de mudanças assertivas para uma nova prática educacional (Altet, 2001).

As sessões eram finalizadas com a avaliação dos procedimentos e com a solicitação de tarefas, que envolviam leitura e reflexão de produções teóricas e elaboração de relatórios semanais sobre as dificuldades encontradas em sala de aula, para serem entregues no encontro seguinte.

\section{Etapa III.}

Reaplicou-se o ECI-B e QRSH-PR referentes aos comportamentos dos alunos com a finalidade de assegurar medidas anteriores e posteriores ao procedimento de formação continuada dos educadores.

Foram realizadas novamente duas filmagens em cada classe, com duração prevista de 20 minutos, com os mesmos cuidados adotados na Etapa 1. O objetivo dessas gravações também foi o de identificar e avaliar a situação de ensino e aprendizagem no cotidiano escolar.

\section{Procedimento de Tratamento e Análise dos Dados}

Foi realizada a comparação entre o grupo de meninos e meninas (Teste Mann-Whitney) para verificar se os grupos eram diferentes quanto às medidas de indicativos de problemas de comportamento (ECI-B) e de repertório socialmente habilidoso (QRSH-PR). Como não foram obtidas diferenças estatísticas, os grupos de meninos e meninas foram tratados como um único grupo, o que norteou as demais análises.

Os resultados relativos aos problemas de comportamento (ECI-B) do repertório comportamental das crianças também foram organizados para as avaliações anteriores e posteriores à intervenção, de forma que escores globais e escores para cada item fossem obtidos e tratados estatisticamente (Teste Qui-Quadrado), considerando a existência ou não de problema de comportamento (0 para não e 1 para sim). Quanto ao QSRH-PR foram comparadas as medidas de pré e pós-teste referentes ao escore total e aos fatores já relatados (Teste Mann-Whitney).

Para se proceder à seleção das filmagens a serem analisadas, as cenas das observações das situações de sala de aula foram assistidas várias vezes, sendo escolhidos dois episódios de cada uma das salas de aula, das cinco educadoras participantes, que melhor retratassem suas práticas pedagógicas, elegendo como critério os momentos em que a educadora estivesse em processo de interação com seus alunos por maior período de tempo. A primeira amostra de cenas se referia às filmagens anteriores à formação continuada 
ofertada e a segunda de momentos posteriores a essa proposta.

Das cenas selecionadas foram analisadas as ações do educador (e, em decorrência, as dos seus respectivos alunos), o que tornou possível definir as temáticas que se destacavam na observação dos videoteipes dos episódios interativos. Em seguida, foi elaborado um sistema de categorias, apresentado na sequência, para análise da prática pedagógica das educadoras, segundo os critérios de exaustividade, exclusividade, nível de amplitude das categorias e nível de inferência, propostos por Sigolo e Biasoli-Alves (1998). As categorias foram definidas segundo um senso de valor, positivo ou negativo, no sentido de se avaliar se as práticas educacionais na interação das educadoras com os alunos favoreceriam ou não o desenvolvimento da cidadania em escolares do $2^{\circ}$ ano do Ensino Fundamental.

\section{Tabela 1}

\section{Sistema de Categorias para Análise da Prática Pedagógica}

Positivas

1. Domínio da sala de aula: o educador consegue manter a classe interessada e envolvida na tarefa proposta, com limites e regras bem estabelecidas em situações prévias;

2. Reflexão: procura fazer com que os alunos reflitam sobre o conteúdo dado, respeitando seu conhecimento prévio e os incentivando a encontrar resposta ou caminho necessário para ela, avançando na aquisição do conhecimento;

3. Crítica: o educador, ao julgar necessário fazer críticas ao comportamento, primeiro elogia o que o aluno fez de forma adequada, depois diz como poderia ter feito melhor e, a seguir, o elogia novamente no que fez de adequado.

4. Atenção individualizada: dá atenção individualizada aos alunos, conforme o grau de dificuldade que apresentam;

5. Oferece suporte à tarefa: o educador oferece pistas verbais ou recursos concretos para os alunos realizarem a tarefa;

6. Reflexão sobre o erro: o educador utiliza-se de respostas erradas dos alunos, estimulando-os a encontrarem a resposta correta;

7. Elogio: elogia as respostas e comportamentos adequados dos alunos;

8. Participação: o educador incentiva a participação dos alunos e consegue motivá-los para a tarefa.
1. Falta de domínio da sala de aula: o educador não consegue ser ouvido ou obedecido pela maior parte dos alunos da classe;

2. Responde pelo aluno: o educador não procura extrair dos alunos o conhecimento prévio que eles têm a respeito do tema, e dá respostas prontas, após questioná-los;

3. Critica o aluno: o educador faz críticas ou chama a atenção do aluno;

4. Atenção homogênea: o educador dá atenção homogênea aos alunos, não levando em conta se há graus de dificuldade diferentes ou não;

5. Ausência de outros recursos: o educador dá a mesma explicação a respeito da tarefa, e, quando não compreendido, repete-a;

6. Não utilização do erro: o educador deixa de utilizar as respostas erradas dos alunos, como recurso de aprendizagem e reflexão para encontrarem a resposta correta;

7. Não reconhecimento: o educador deixa de elogiar ou reconhecer as respostas e comportamentos adequados dos alunos;

8. Não incentiva: o educador não incentiva a participação dos alunos e não consegue mantê-los motivados para a realização da tarefa.
Nas cenas escolhidas foram averiguadas as ocorrências das categorias para cada filmagem selecionada de cada educadora. Para se garantir maior fidedignidade na análise das filmagens, dois pesquisadores elaboraram o sistema de categorias e a classificação das filmagens foi realizada individualmente, obtendo-se índice de concordância de 100\% (Kazdin, 1982). 


\section{Resultados e Discussão}

Serão apresentados inicialmente os resultados do repertório das crianças relatados pelas educadoras (ECI-B e QRSH-Pr) antes e depois da intervenção com as educadoras e, depois, a análise das filmagens.
A Figura 1 apresenta o número de crianças com indicativos de problemas de comportamento e sem indicativos, nas medidas obtidas nas Etapas A (antes da intervenção) e C (depois da intervenção), segundo as educadoras.

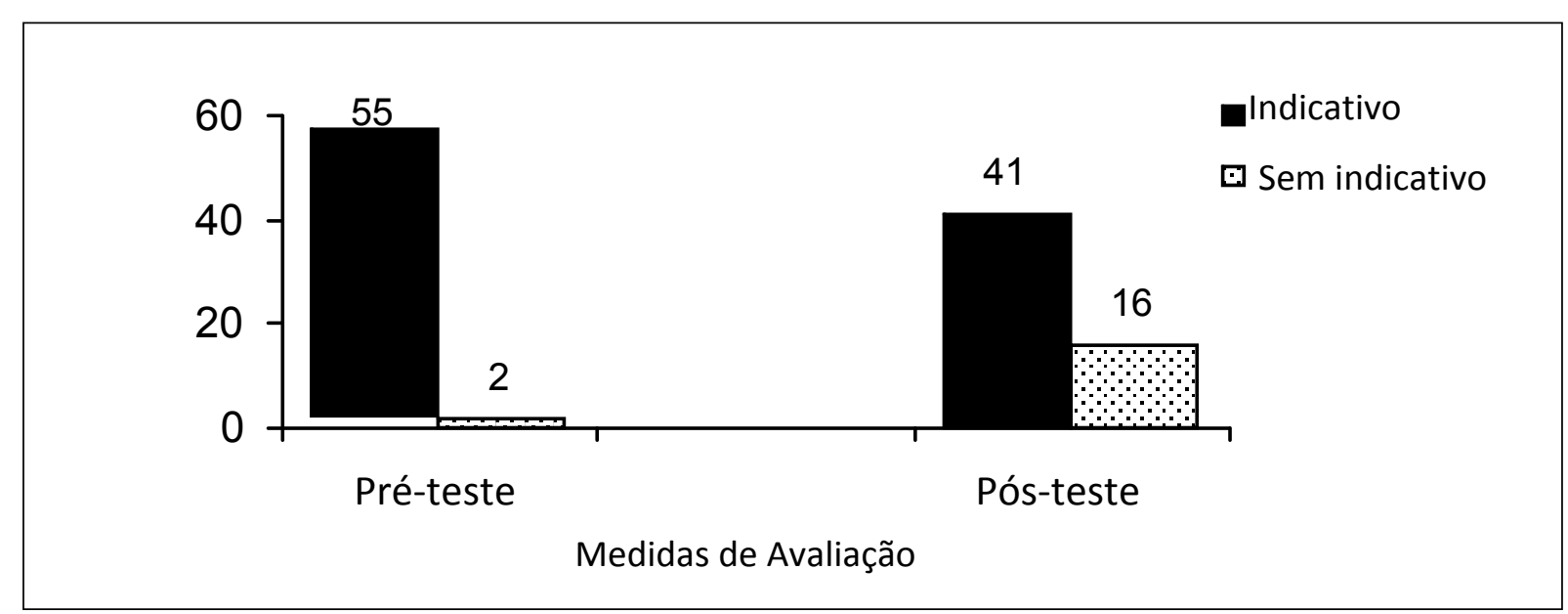

Figura 1. Comparação das medidas antes e depois da intervenção com os alunos (com e sem indicativos de Problemas de Comportamento - ECI/B).

Verifica-se redução do número de crianças indicadas como tendo problemas de comportamento (de $48,7 \%$ para $36,3 \%$ ), no pós-teste. $\mathrm{O}$ teste Qui-Quadrado $2 \times 2$ indicou diferença estatística significativa $(p=0,021)$. Estes dados indicam que, apesar da formação continuada oferta- da ter sido realizada em curto prazo, com número reduzido de sessões, intervir pontualmente com educadores parece ser promissor para reduzir a ocorrência de problemas de comportamento por parte dos alunos e, consequentemente, aumentar o indicativo de casos não-clínicos.

Tabela 2

Comparações Pré e Pós-Testes dos Fatores do QRSH-Pr (Teste Mann-Whitney)

\begin{tabular}{lccc}
\hline Fatores do QRSH-Pr & $\begin{array}{c}\text { Pré-teste } \\
\text { Média }\end{array}$ & $\begin{array}{c}\text { Pós-teste } \\
\text { Média }\end{array}$ & $p$ \\
\hline Fator Sociabilidade (15 itens) & 16,86 & 19,26 & 0,004 \\
Fator Iniciativa (6 itens) & 6,40 & 6,39 & - \\
Fator Busca de Suporte (3 itens) & 4,36 & 4,28 & - \\
Item “não se deixa intimidar" & 1,39 & 1,23 & - \\
\hline Total do QRSH-PR & 34,44 & 67,96 & 0,000 \\
\hline
\end{tabular}

A Tabela 2 ilustra uma comparação das medidas de pré e pós-teste das médias totais obtidas com o instrumento QRSH-Pr que aponta aumento significativo do escore total e do fator Sociabilidade na medida de pós-teste, no relato de desempenhos socialmente habilidosos das crianças, segundo relatos de suas educadoras. Pesquisadores afirmam que comportamentos socialmente habilidosos previnem o surgimento de problemas de comportamento (Del Prette \& Del Prette, 2002; M. C. T. Ferreira \& Marturano, 2002), porque quando as crianças interagem 
mais positivamente com as pessoas de sua convivência, diminui a possibilidade de apresentação de comportamentos inadequados, permitindo que a criança encontre contingências relevantes para a aprendizagem, seja social ou acadêmica.

Os dois instrumentos aplicados tiveram seus resultados corroborados na medida em que tanto a apresentação de problemas de comportamento como as respostas socialmente habilidosas apresentaram alteração significativa após a intervenção, exibindo diminuição de problemas e aumento de respostas sociais hábeis.

A seguir, na Figura 2, encontram-se os resultados obtidos por intermédio da análise das filmagens das educadoras, em situações de interação com seus alunos em sala de aula, em momentos distintos: antes e depois da formação continuada ofertada.

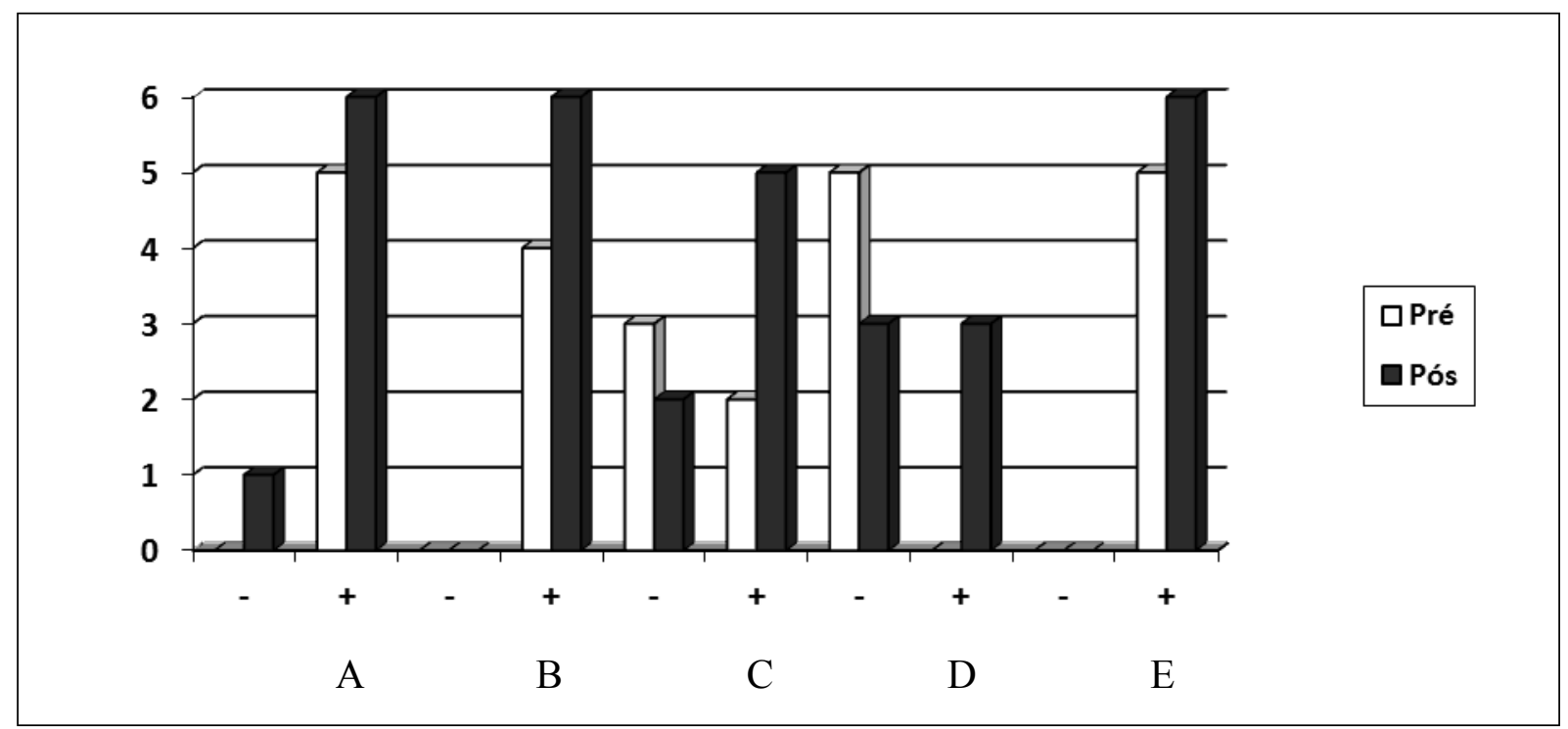

Figura 2. Frequência de comportamentos das educadoras - A, B, C, D, E - categorizados como Positivos (+) ou Negativos (-), antes e depois da intervenção.

Na Figura 2 encontra-se a frequência de categorias de comportamentos julgados como negativos e positivos - conforme anunciado no sistema de categorias apresentado - na análise das filmagens realizadas antes e depois da intervenção com as cinco educadoras. Pode-se observar que duas educadoras (C e D) apresentaram comportamentos categorizados como negativos na pré-filmagem e que esses comportamentos diminuíram na filmagem posterior à formação continuada, como também, tiveram maior aumento nos comportamentos positivos.

É possível observar acréscimo de comportamentos positivos em todas as educadoras assim como a diminuição de comportamentos negativos, com exceção da educadora $\mathrm{A}$, que não apresentou comportamento negativo antes da intervenção, mas apresentou uma categoria negativa na filmagem depois da intervenção, porém a maioria de seus comportamentos foi positivo tanto no pré como no pós-teste.
Em alusão às categorias definidas no sistema de classificação de categorias apresentado, percebe-se que as práticas das educadoras após a intervenção envolveram um número maior de comportamentos que indicavam maior participação dos alunos nas atividades propostas, incentivando-os e auxiliando-os nas proposições acadêmicas.

Quando o educador apresentava categorias que indicavam comportamentos positivos na sua prática, considerou-se que seu ensino voltava-se para o desenvolvimento de competências relacionadas à análise crítica dos conteúdos acadêmicos, contribuindo assim para a formação de alunos mais participativos e questionadores do contexto em que estão inseridos. Nessa perspectiva, a efetivação de tais comportamentos pode atuar como pré-requisito para a consolidação de repertórios pró-éticos. Recorda-se que repertórios pró-éticos representam classes de respostas que compõem comportamentos que funcionam 
como pré-requisitos para a formação cidadã dos alunos, respeitados os limites do contexto escolar, que é apenas parcela (embora significativa) do contexto social mais amplo.

Fazendo um cotejo dos dados demonstrados percebe-se que a maioria das educadoras já apresentava comportamentos considerados como adequados na sua prática pedagógica. Entretanto, observou-se que essa incidência aumentou após o processo de intervenção dos pesquisadores. Tais dados vêm reforçar a importância da oferta de propostas de formação continuada de educadores. Acredita-se que a análise dos episódios que retratavam a prática educacional vivenciada pelo educador, por meio do uso das filmagens em sala de aula, possibilitou às educadoras refletirem e repensarem, conjuntamente com os pesquisadores, suas práticas educativas. Com essas ações percebeu-se a menor incidência de comportamentos julgados como negativos, nos resultados obtidos após a intervenção, além de maior manifestação de situações educacionais consideradas positivas no processo de ensino e aprendizagem. Esses dados sugerem que a mudança evidenciada na prática pedagógica das educadoras pode ainda indicar a promoção de comportamentos pró-éticos nos alunos da realidade escolar investigada.

\section{Considerações Finais}

Acredita-se que para compreender o desenvolvimento social da criança é importante avaliar as interações estabelecidas entre ela e o adulto. Bolsoni-Silva e Marturano $(2007,2008)$ apontam que interações sociais positivas de adultos com crianças (pautadas no respeito mútuo, na expressão de opiniões, de sentimentos positivos e de afeto, na consistência e no estabelecimento de limites) previnem o surgimento de problemas de comportamento e promovem comportamentos socialmente habilidosos. Saber comportar-se de forma socialmente habilidosa possivelmente contribui para a aquisição de comportamentos pró-éticos, já que são ensinados para a criança comportamentos que efetivamente resolvem problemas, sem, contudo, haver necessidade de infringir as normas sociais compatíveis com o exercício da cidadania.
Esta pesquisa propôs um conjunto de intervenções que visavam, de maneira geral, dar condições para educadores manejarem problemas de comportamento de alunos em sala de aula, visando uma conduta em favor da ética e valores que incluem a diversidade social. O programa instrucional consistiu não só na apresentação de um rol de comportamentos socialmente habilidosos para o manejo de situações conflitantes em sala de aula, mas propiciou oportunidades para que o educador discriminasse as condições de sala de aula, observasse os efeitos dessas ações sobre o seu relacionamento com os alunos e analisasse a relação entre os alunos.

Os resultados desta pesquisa evidenciam a diminuição de frequência de problemas de comportamento e aumento de frequência de comportamentos socialmente habilidosos dos alunos. Nesse contexto, conforme relatado por Oliveira (2001), os princípios éticos e morais escolhidos numa ação educativa só adquirem sentido prático e são legitimados na medida em que o caráter abstrato e geral das históricas dissensões filosóficas sobre ética e moral é superado e confrontado diretamente com a realidade vivida.

Os achados do presente trabalho parecem indicar que a adoção de estratégias de formação continuada estruturada, em face de repertórios concretamente aferidos dos educadores, assegura o aprimoramento das interações destes com seus alunos, no sentido da instalação e consolidação de comportamentos sociais pró-éticos e compatíveis com o desenvolvimento de repertório socialmente habilidoso e eticamente comprometido com a cidadania. Diante de tais dados, que indicam o envolvimento dos docentes e a sensibilidade dos alunos às contingências programadas, parece auspicioso o emprego de procedimentos sistemáticos de ensino mediante rearranjo de contingências para formação continuada dirigida a temas transversais relevantes, como o da ética nas relações interpessoais, a partir do contexto escolar.

Comportamentos das educadoras que incentivam a capacidade reflexiva do aluno, que valorizam e respeitam o conhecimento prévio do educando, que estimulam a sua participação e fornecem suporte individualizado, quando necessário, propiciam ao aluno desenvolver sua ca- 
pacidade reflexiva e crítica, seguir o modelo de respeito e valorização com que é tratado, estendendo-o às pessoas de seu convívio. Tais indicativos resultam numa relação de trocas interacionais em sala de aula mais adequadas, podendo estendê-las para outros contextos sociais, além de melhorar a autoestima nos personagens que compõem o cenário de sala de aula, promovendo assim comportamentos pró-éticos no ambiente educacional.

Por fim, no desenvolvimento da pesquisa observou-se que a participação dos pesquisadores na unidade escolar investigada produziu a análise da prática pedagógica dos educadores de $2^{\circ}$ ano do ensino fundamental. Recorda-se que a formação continuada é um direito garantido pela LDB n ${ }^{\circ} 9.394 / 96$, art. 61 e 67 , e deve se tornar um continuum de ações efetivas para a melhoria do sistema educacional. Nessa direção Prada, Palma e Passos (2001), destacam que a reflexão conjunta dos pesquisadores com os educadores sobre experiências cotidianas, à luz de preceitos teóricos, materializam a construção de novos conhecimentos e reorganizam o panorama educacional, promovendo melhorias na qualidade do ensino público.

\section{Referências}

Achenbach, T. M., \& Edelbrock, C. S. (1979). The child behavior profile: II. Boys aged 12-16 and girls aged 6-11 and 12-16. Journal of Consulting and Clinical Psychology, 47(2), 223-233.

Altet, M. (2001). As competências do professor profissional: Entre conhecimentos, esquemas de ação e adaptação, saber analisar. In P. Perrenoud, L. Paquay, M. Altet, \& E. Charlier (Orgs.), Formando professores profissionais: Quais estratégias? Quais competências? (pp. 23-32) Porto Alegre, RS: Artmed.

Betetto, M. F., \& Carrara, K. (2009). Educação, transformação social e cidadania: Uma investigação de habilidades sociais medidas pelo Inventário de Habilidades Sociais. Estudos de Psicologia (Campinas), 26(3), 337-347.

Bolsoni-Silva, A. T. (2008). Roteiro de Entrevista de Habilidades Sociais Educativas Parentais (RE-HSE-P): Categorias e testagem preliminares. In L. D. Weber (Org.), Família e Desenvolvimento - Visões interdisciplinares (pp. 145-158). Curitiba, PR: Juruá.
Bolsoni-Silva, A. T., \& Del Prette, A. (2003). Problemas de comportamento: Um panorama da área. Revista Brasileira de Terapia Comportamental e Cognitiva, 5(2), 91-103.

Bolsoni-Silva, A. T., \& Marturano, E. M. (2007). A qualidade da interação positiva e da consistência parental na sua relação com problemas de comportamento de pré-escolares. Revista Interamericana de Psicologia, 41(3), 349-358.

Bolsoni-Silva, A. T., \& Marturano, E. M. (2008). Habilidades Sociais Educativas Parentais e problemas de comportamento: Comparando pais e mães de pré-escolares. Revista Aletheia, 27(1), 126-138.

Bolsoni-Silva, A. T., Marturano, E., \& Loureiro, S. R. (2009). Construction and validation of the Brazilian Questionário de Respostas Socialmente Habilidosas segundo Relato de Professores (QRSH-PR): The Spanish Journal of Psychology, 12(1), 349-359.

Caballo, V. E. (1991). El entrenamiento en habilidades sociales. In V. E. Caballo (Org.), Terapia y modificacion de conducta (pp. 403-443). Madrid, España: Siglo Veintiuno.

Caballo, V. E. (1995). Una aportación española a los aspectos moleculares, a la evaluación y al entrenamiento de las habilidades sociales. Revista Mexicana de Psicologia, 12(2), 121-131.

Caldarella, P., \& Merrell, K. W. (1997). Common dimensions of social skills of children and adolescents: A taxonomy of positive behaviors. School Psychology Review, 26(2), 264-278.

Carrara, K. (1996). A Psicologia e a construção da cidadania. Psicologia: Ciência e Profissão, 16(1), 12-17.

Carrara, K. (1999). Educação, transformação social e cidadania. Manuscrito de áudio não publicado para vídeo elaborado para o programa Universidade Solidária, especialmente para a comunidade educacional de Tomar do Geru (SE).

Carrara, K. (2000). Contextualismo, contracontrole e cidadania. Revista da APG, 21, 23-38.

Conselho Nacional de Saúde. (1998). Resolução $n^{\circ}$ 196/96 sobre pesquisas envolvendo seres humanos. Decreto $\mathrm{n}^{\circ}$. 93.933, de 14 janeiro de 1998. Bioética, 7(2, Supl.).

Del Prette, Z. A. P., \& Del Prette, A (2003). Aprendizagem sócio-emocional na infância e prevenção da violência: Questões conceituais e metodologia da intervenção. In A. Del Prette \& Z A P. Del Prette (Orgs.), Habilidades sociais, desenvolvi- 
mento e aprendizagem: Questões conceituais, avaliação e intervenção (pp. 83-127). Campinas, SP: Alínea.

Del Prette, Z. A. P., \& Del Prette, A. (2002). Avaliação de habilidades sociais de crianças com um inventário multimídia: Indicadores sociométricos associados a frequência versus dificuldade. Psicologia em Estudo, 7(1), 61-73.

Dessen, M. A. (1996). Tecnologia de vídeo: Registro de interações sociais e cálculos de fidedignidade em estudos observacionais. Psicologia: Teoria e Pesquisa, 11(3), 223-227.

Ferreira, M. C. T., \& Marturano, E. M. (2002). Ambiente familiar e os problemas do comportamento apresentados por crianças com baixo desempenho escolar. Psicologia: Reflexão e Crítica, 15(1), 35-44.

Ferreira, M. F., \& Carrara, K. (2009). Implicações do conceito de cidadania de professores sobre comportamentos pró-éticos de estudantes. Psicologia Argumento, 27, 219-229.

Kazdin, A. E. (1982). Single case research designs: Methods for clinical and applied settings. New York: Oxford University Press.

Lei ${ }^{\circ}$ 9.394, de 20 de dezembro de 1996. (1996, 23 dez.). Estabelece as diretrizes e bases da educação nacional. Diário Oficial da União.

Leite, L. P. (2003). A intervenção reflexiva como instrumento de formação continuada do educador: Um estudo em classe especial (Tese de doutorado em Educação, Faculdade de Filosofia e Ciências, Universidade Estadual Paulista Júlio de Mesquita Filho, Marília, SP, Brasil).

Leite, L. P., \& Aranha, M. S. F. (2005). Intervenção reflexiva: Instrumento de formação continuada do educador especial. Psicologia: Teoria e Pesquisa, 21(1), 207-215.

Menin, M. S. S. (2002). Valores na escola. Educação \& Pesquisa, 28(1), 91-100.

Ministério da Educação e do Desporto. (1998). $R C$ NEI - Referencial Curricular Nacional para a Educação Infantil. Brasília, DF: Autor.

Ministério da Educação e do Desporto. (1999). PCN - Parâmetros Curriculares Nacionais: Adaptações Curriculares - Estratégias para a educação de alunos com necessidades educacionais especiais. Brasília, DF: Autor.
Ministério da Educação. (2004). Programa de Desenvolvimento Profissional Continuado. Módulo I: Ética. Brasília, DF: Autor.

Nucci, L. (2000). Psicologia Moral e Educação: Para além de crianças "boazinhas". Educação e Pesquisa, 26(2), 71-89.

Oliveira, R. J. (2001). Ética na escola: (Re)acendendo uma polêmica. Educação \& Sociedade, 22(76), 212-231.

Prada, L. E. A., Palma, J. C., Filho, \& Passos, L. F. (2001). Educação continuada: O discurso oficial, a política e a utopia. In VI Congresso Estadual Paulista sobre formação de educadores (pp. 7790). São Paulo, SP: Águas de Lindóia.

Rocha, J. F., \& Carrara, K. (2011). Formação ética para a construção da cidadania: Reorganizando algumas contingências na interação professor-aluno. Psicologia Escolar e Educacional, 15, 221-230.

Rosales-Ruiz, J., \& Baer, D. M. (1997). Behavioral cusps: A developmental and pragmatic concept for behavior analysis. Journal of Applied Behavior Analysis, 30, 533-544.

Santos, P. L. (2002). Riscos e recursos em crianças com alto e baixo rendimento acadêmico: Um estudo comparativo (Tese de doutorado, Universidade de São Paulo, Ribeirão Preto, SP, Brasil).

Sigolo, S. R. R. L., \& Biasoli-Alves, Z. M. M. (1998). Análise de dados de interação mãe-criança Construção de sistemas de categorias. In G. Romanelli \& Z. M. M. Biasoli-Alves (Orgs.), Diálogos metodológicos sobre prática de pesquisa (pp. 87-118). Ribeirão Preto, SP: Legis Summa.
Recebido: 19/04/2012

Primeira revisão: 06/08/2012

Segunda revisão: 19/09/2012 Aceite final: 02/02/2013 